\section{(6) OPEN ACCESS}

\title{
Breath-taking jobs: a case-control study of respiratory work disability by occupation in Norway
}

\author{
AKM Fell, ${ }^{1}$ R Abrahamsen, ${ }^{1,2}$ PK Henneberger, ${ }^{3}$ MV Svendsen, ${ }^{1}$ E Andersson, ${ }^{4}$ \\ $\mathrm{K}$ Torén, ${ }^{4}$ J Kongerud ${ }^{2,5}$
}

${ }^{1}$ Department of Occupational and Environmental Medicine, Telemark Hospital, Skien, Norway

${ }^{2}$ Faculty Division Rikshospitalet, University of Oslo, Norway

${ }^{3}$ National Institute for

Occupational Safety and Health (NIOSH), Morgantown, West Virginia, USA

${ }^{4}$ Department of Occupational and Environmental Medicine, Institute of Medicine, The Sahlgrenska Academy, University of Gothenburg, Gothenburg, Sweden ${ }^{5}$ Department of Respiratory Medicine, Oslo University Hospital, Oslo, Norway

\section{Correspondence to} AKM Fell, Department of Occupational and

Environmental Medicine, Telemark Hospital, Ulefossveien 55, 3710, Skien, Norway; annfel@sthf.no

Received 3 December 2015 Revised 27 May 2016 Accepted 31 May 2016 Published Online First 30 June 2016

\section{ABSTRACT}

Background The current knowledge on respiratory work disability is based on studies that used crude categories of exposure. This may lead to a loss of power, and does not provide sufficient information to allow targeted workplace interventions and follow-up of patients with respiratory symptoms.

Objectives The aim of this study was to identify occupations and specific exposures associated with respiratory work disability.

Methods In 2013, a self-administered questionnaire was mailed to a random sample of the general population, aged 16-50, in Telemark County, Norway. We defined respiratory work disability as a positive response to the survey question: 'Have you ever had to change or leave your job because it affected your breathing?' Occupational exposures were assessed using an asthma-specific job-exposure matrix, and comparison of risks was made for cases and a median of 50 controls per case.

Results 247 workers had changed their work because of respiratory symptoms, accounting for $1.7 \%$ of the respondents ever employed. The 'breath-taking jobs' were cooks/chefs: adjusted OR $3.6(95 \% \mathrm{Cl} 1.6$ to 8.0$)$; welders: 5.2 (2.0 to 14); gardeners: 4.5 (1.3 to 15$)$; sheet metal workers: 5.4 (2.0 to 14); cleaners: 5.0 (2.2 to 11); hairdressers: 6.4 (2.5 to 17$)$; and agricultural labourers: 7.4 (2.5 to 22). Job changes were also associated with a variety of occupational exposures, with some differences between men and women.

Conclusions Self-report and job-exposure matrix data showed similar findings. For the occupations and exposures associated with job change, preventive measures should be implemented.

\section{INTRODUCTION}

It is recognised that work disability is costly to the individual and society. ${ }^{1}$ Job change due to breathing problems at work is common and may be associated with exposure to irritants and dust in the workplace. $^{2-4}$ This was first shown in crosssectional studies, ${ }^{2} 4$ and then, in 2009, in a large prospective population-based study from Europe and the USA. ${ }^{4}$ The latter study detected an incidence of 1.2/1000 person-years for new-onset respiratory work disability. The current knowledge on respiratory work disability is based on studies that use crude categories of exposure, such as ever having been exposed to vapours, gases, dust or fumes (VGDF) at work. This may lead to loss of power ${ }^{5}$ and does not provide sufficient information

\section{What this paper adds}

- The current knowledge on respiratory work disability is based on studies that use crude categories of exposure, which do not provide sufficient information for targeted workplace interventions and follow-up of patients with respiratory symptoms.

- The aim of the study was to identify occupations and specific exposures associated with respiratory work disability.

- The 'breath-taking jobs' were cook/chef, welder, gardener, sheet metal worker, cleaner, hairdresser and agricultural labourer.

- Several specific occupational exposures were associated with an increased risk of job change, with some differences between genders.

- Our findings indicate that preventive measures are still needed to prevent workers from being forced to leave their workplace because exposures at work affect their breathing.

for targeted workplace interventions and follow-up of patients with respiratory symptoms.

Respiratory work disability may be defined in different ways, with complete cessation of employment being the most severe manifestation. Lost workdays, limitations in job tasks or reduction in work hours, and change of workplace can also be used to define work disability, and are shown to have large health and socioeconomic impacts. ${ }^{6}$

The aetiology of work disability is probably multifactorial, ${ }^{1}$ and includes interactions between the person and the environment in which they live and work. For work-related respiratory disability, the working environment may cause or aggravate the health problem. It is established that occupational exposure can promote respiratory disability, ${ }^{2-4}$ and having a disease, particularly a severe disease, has been shown to be a strong predictor for respiratory work disability. ${ }^{67}$ While the individual ability to balance limitations in activities following respiratory symptoms with the demands that participation in working life imposes varies, the reduction of exposure in the workplace will be feasible in most cases. However, so far it has been challenging to conduct targeted interventions because there is limited information regarding groups at risk. 
The aim of our study was to identify specific occupations and exposures associated with respiratory work disability by using the International Standard Classification of Occupations (ISCO 88$)^{8}$ and an asthma-specific job-exposure matrix (JEM) on a large random sample from the general population. The study was based on the first cross-sectional analysis of a prospective study from Telemark, Norway (the Telemark Study). A variety of occupational exposures may occur in the county of Telemark, from the diversity of large and small industrial companies in the south-west to agricultural activities in other parts.

\section{MATERIAL AND METHODS Study participants}

The Telemark Study is a longitudinal population study that began with a cross-sectional survey performed from February to September 2013 in Telemark, Norway. Telemark County is located in the south-eastern part of Norway and has a population of $\sim 170000$ inhabitants. The south-western part of the county, which includes four municipalities with a total population of 100000 inhabitants, has historically been the largest onshore industrialised area in Norway. A random sample of 50000 inhabitants in Telemark, aged 16-50, was selected from the national registry, which contained the social security code, date of birth, gender and address for each person.

\section{Study design \\ Questionnaire}

A self-administered questionnaire based on the European Community Respiratory Health Survey questionnaire ${ }^{10}$ and the West Sweden Asthma Study questionnaire ${ }^{11}$ regarding respiratory symptoms and conditions, and occupational exposures, was mailed to the sample of 50000 inhabitants. The response rate was 33\%, comprising 16099 responders. A subset of non-responders was asked to answer a limited number of questions with the same wording as in the original questionnaire. ${ }^{12}$ Non-response was associated with younger age (nonresponders were 2.4 years younger) and being male (71\% of the eligible men and $62 \%$ of the eligible women were nonresponders). Past smoking was significantly less common among responders $(20.9 \%)$ than non-responders $(29.6 \%)$, but current smoking levels were similar: $24.0 \%$ versus $23.7 \%$. Responders and non-responders reported similar frequencies of wheezing during the past 12 months (20.5\% and $21.3 \%$, respectively), and nasal allergies $(30.8 \%$ and $31.6 \%$, respectively). Employment status in the past 12 months and the frequency of self-reported occupational exposures to VGDF did not vary substantially by responder status.

We defined respiratory work disability as a positive response to the survey question 'Have you ever had to change or leave your job because it affected your breathing?' Physician-diagnosed asthma was defined as a positive response to the question 'Have you been diagnosed by a physician as having asthma?' The presence of respiratory symptoms in the past 12 months was based on an affirmative response to the respective questions regarding wheezing: 'Have you had whistling or wheezing in the chest at any time during the past 12 months?'; chest tightness: 'Have you woken up with a feeling of tightness in your chest at any time during the past 12 months?'; and dyspnoea: 'Have you woken up with dyspnoea at any time during the past 12 months?' Nasal allergy was defined as a positive response to the question: 'Do you have an allergy that causes nasal symptoms, including hay-fever?'

\section{Occupational exposure}

Questions addressing occupational exposure to specific agents (eg, epoxy or acrylates) and work tasks (eg, welding, cleaning or disinfecting) were included in the postal questionnaire. In addition, the responders were asked to list their occupational history. We used a JEM developed for the northern European countries (N-JEM) ${ }^{13}{ }^{14}$ to assess exposure based on the selfreported occupations 1 year prior to the year in which respondents stated that they had changed their jobs due to respiratory symptoms. The N-JEM was developed using the same methods as other JEMs ${ }^{1015}$ and is based on the ISCO- 88 codes of occupation. A few job titles specific to industries in Telemark County were added to the N-JEM. In the N-JEM, an exposed occupation is defined on the basis of the assumption that at least half of the participants with this specific code should have a high probability of being exposed to the critical agents. The N-JEM includes six main exposure groups: high-molecular-weight (HMW) agents, low-molecular-weight agents, irritating agents, accidental peak exposure to irritants, uncertain or low exposure, and an unexposed reference group. ${ }^{13}$

\section{Inclusion of cases and controls}

For the analysis of the association of job change with selfreported occupational exposure, we included the complete sample of 16099 from the population study. Among all 247 participants who reported that they had changed jobs due to respiratory symptoms, a subset had also specified their job in the year prior to the change. The individuals in this subset were considered cases in the case-control analyses. In these analyses, we used the job code for the year prior to job change for cases and the job code registered for the appropriate corresponding time point in the work history for controls. This selection was performed by pooling all controls from each birth year and randomising the year of employment, resulting in comparable time points in the occupational history for cases and controls. Each participant only served as a control for one case. A total of 8352 controls were randomised for the 125 cases, and the number of controls for each case ranged from 20 to 249 , with a median of 50. Figure 1 shows the inclusion and selection of cases and controls.

\section{Statistical analysis}

The size of the Telemark study was chosen on the basis of sample sizes in similar studies. ${ }^{2} \chi^{2}$ Tests were used to compare the case and control groups with regard to the prevalence of respiratory symptoms. To estimate the effects of ever being exposed to specific occupational agents, the ORs and corresponding 95\% CIs were computed. Owing to correlations between the exposures, principal component analysis (PCA) with varimax rotation was used to reduce the number of variables to a few interpretable linear combinations of the data. Six interpretable and independent factors were identified and estimated. Logistic regression was used to estimate the effect of exposure on job change. ORs were calculated for the total sample, and stratification by gender was performed where appropriate.

The estimates were adjusted for age and smoking status, as well as for gender when not stratified by gender. The statistical significance level was set at $\mathrm{p}<0.05$ and results reaching significance are marked in bold in the tables. Statistical analysis was performed using IBM SPSS Statistics for Windows (V.21.0, IBM SPSS, Armonk, New York, USA). 


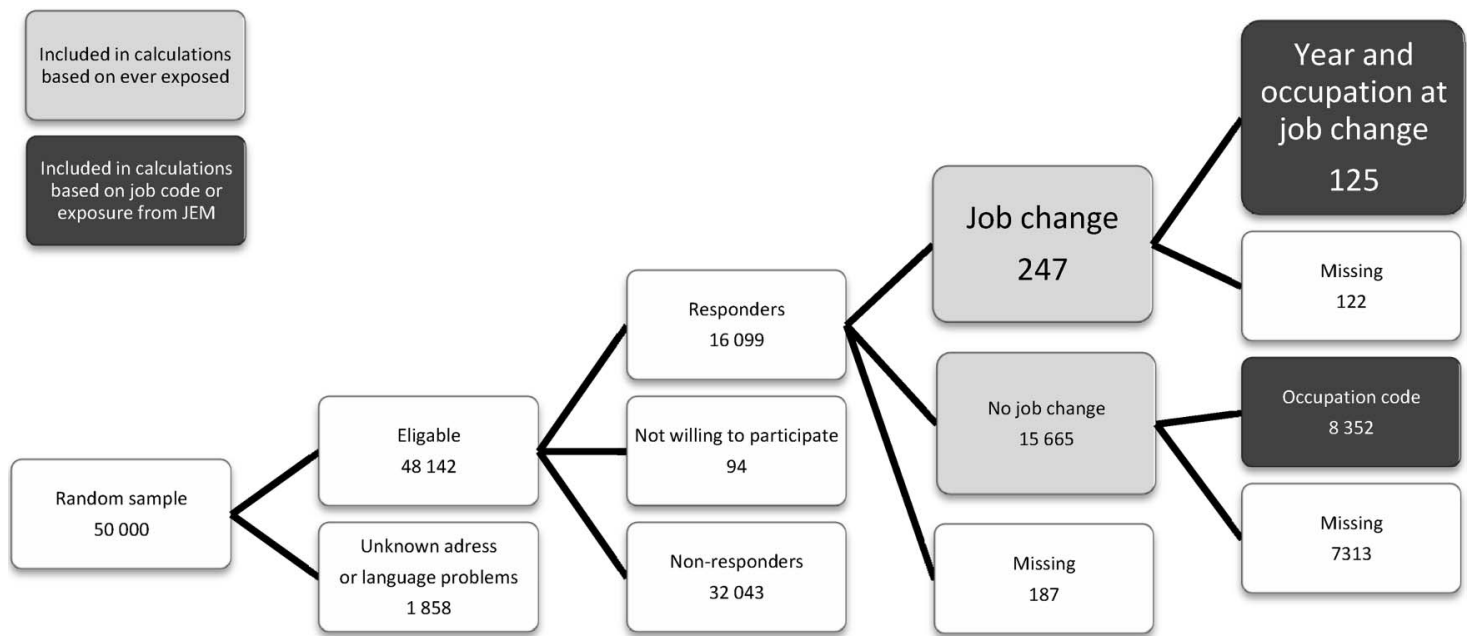

Figure 1 Inclusion of participants reporting job change because work affected their breathing $(n=247)$, and of those with a year and an occupation listed for the time point of the job change $(n=125)$. JEM, job-exposure matrix.

\section{RESULTS}

\section{Analyses with all participants}

Two hundred and forty-seven workers had changed their work due to respiratory symptoms, accounting for $1.7 \%$ of the 14906 respondents who were ever employed and $1.5 \%$ of all 16099 respondents. Of the total sample, $2.2 \%$ of men $(n=141)$ and $1.3 \%$ of women $(n=106)$ had changed their workplace because exposures at work affected their breathing.

Forty-nine per cent of all respondents who had ever been employed reported being exposed to VGDF at work and 17\% reported exposure on a daily basis in the past 5 years. Eighty-four per cent of the 247 workers who changed their jobs due to respiratory symptoms had been exposed to VGDF compared with $48.6 \%$ among the ever employed controls $(\mathrm{OR}=5.6$, $95 \%$ CI 4.0 to 8.0 , adjusted for age, gender, and smoking). We analysed the most prevalent self-reported single exposures among those ever employed and associated with workplace change due to respiratory symptoms. The frequency and ORs of these exposures were: cleaning/disinfection agents $(58 \%$, $\mathrm{OR}=1.7,95 \%$ CI 1.3 to 2.2 ); low temperatures (52\%, $\mathrm{OR}=1.9,95 \%$ CI 1.5 to 2.5$)$; metal dust $(40 \%, \mathrm{OR}=3.7,95 \%$ CI 2.8 to 4.8$)$; welding fumes $(40 \%, \mathrm{OR}=3.6,95 \%$ CI 2.8 to 4.8 ); and paint (37\%, OR=3.2 95\% CI 2.4 to 4.2$)$.

Some of the self-reported exposures were correlated, thus principal component analysis (PCA) was performed and six

Table 1 Risk of job change due to respiratory symptoms by self-reported occupational exposure (ever) and gender*

\begin{tabular}{|c|c|c|c|}
\hline Exposure group & $\begin{array}{l}\text { Total } \\
\left(\mathrm{n}_{\text {cases }}=247\right) \\
(0 \mathrm{R}, 95 \% \mathrm{Cl}) \dagger\end{array}$ & $\begin{array}{l}\text { Females } \\
(n=106) \\
(0 R, 95 \% \text { Cl }) \neq\end{array}$ & $\begin{array}{l}\text { Males }(n=141) \\
(0 R, 95 \% \mathrm{Cl}) \ddagger\end{array}$ \\
\hline Metals/gases & 1.5 (1.3 to 1.7$)$ & 1.3 (1.1 to 1.5$)$ & 1.6 (1.3 to 1.9$)$ \\
\hline Damp/mould & 1.1 (1.0 to 1.3 ) & 1.2 (1.0 to 1.4$)$ & 1.1 (0.88 to 1.2$)$ \\
\hline Exercise/cold & 1.6 (1.3 to 1.8$)$ & 1.5 (1.2 to 1.9$)$ & 1.7 (1.4 to 2.2 ) \\
\hline Cleaning/cooking & 1.3 (1.1 to 1.4$)$ & 1.3 (1.1 to 1.4$)$ & 1.0 (0.86 to 1.2$)$ \\
\hline Organic dust & 1.1 (0.98 to 1.2$)$ & $1.1(0.92$ to 1.3$)$ & 1.1 (0.99 to 1.3$)$ \\
\hline $\begin{array}{l}\text { Hair products/ } \\
\text { animals }\end{array}$ & 1.2 (1.1 to 1.4$)$ & 1.2 (0.98 to 1.4$)$ & $1.0(0.87$ to 1.2$)$ \\
\hline
\end{tabular}

${ }^{*}$ Models included 14906 participants who had ever been employed.

tAdjusted for age, gender and smoking.

$\ddagger$ Adjusted for age and smoking. exposure groups identified. These analyses showed that workers exposed to metals/gases, exercise/cold, cleaning/cooking and hair products/animals had an increased risk of job change because work affected their breathing compared with those who did not report such exposure (table 1).

\section{Case control analyses}

One hundred and twenty-five cases had specified a year for their change of workplace and listed an occupation for that time point in their occupational history. The population characteristics for these cases and their 8352 matched controls by gender are shown in table 2. Respiratory symptoms, physiciandiagnosed asthma and nasal allergy were significantly $(\mathrm{p}<0.001)$ more prevalent in cases than in controls. The population characteristics for all 247 cases, including the 122

Table 2 Population characteristics for participants reporting a job change because the work affected their breathing (125 cases), and matched controls

\begin{tabular}{|c|c|c|c|c|}
\hline \multirow[b]{2}{*}{$\begin{array}{l}\text { Variable } \\
\text { (\% of valid)* }\end{array}$} & \multicolumn{2}{|l|}{ Controls } & \multicolumn{2}{|c|}{$\begin{array}{l}\text { Cases specifying job } \\
\text { in year prior to } \\
\text { change }\end{array}$} \\
\hline & $\begin{array}{l}\text { Females } \\
(n=4592)\end{array}$ & $\begin{array}{l}\text { Males } \\
(n=3760)\end{array}$ & $\begin{array}{l}\text { Females } \\
(n=47)\end{array}$ & $\begin{array}{l}\text { Males } \\
(n=78)\end{array}$ \\
\hline Mean age in years & 38.4 & 39.4 & 39.6 & 40.4 \\
\hline \multicolumn{5}{|l|}{ Smoking } \\
\hline Never smoked & $2268(50.6)$ & $1814(49.2)$ & $19(40)$ & $31(40)$ \\
\hline Ex-smoker & $1087(24.2)$ & $903(24.5)$ & $12(26)$ & $21(27)$ \\
\hline Current smoker & $1130(25.2)$ & $967(26.2)$ & $16(34)$ & $25(32)$ \\
\hline \multicolumn{5}{|c|}{ Asthma symptoms in past 12 months: } \\
\hline Wheezing & $955(21.2)$ & $754(20.3)$ & $27(60)$ & $42(56)$ \\
\hline Chest tightness & $698(15.6)$ & 448 (12.2) & $25(56)$ & $38(51)$ \\
\hline Dyspnoea & $307(6.9)$ & $261(7.2)$ & $17(38)$ & $29(38)$ \\
\hline $\begin{array}{l}\text { Physician-diagnosed } \\
\text { asthma }\end{array}$ & $490(11.0)$ & $395(10.8)$ & $28(64)$ & $34(45)$ \\
\hline $\begin{array}{l}\text { Symptoms prior to } \\
\text { age } 16\end{array}$ & $307(66.5)$ & $243(64.3)$ & $12(44)$ & 19 (56) \\
\hline Nasal allergy & $1387(30.9)$ & 1154 (31.4) & $30(67)$ & $43(55)$ \\
\hline
\end{tabular}


without a specified year and a listed occupation, were similar (not reported).

To assess specific exposures associated with job change, we performed a more detailed analysis among the 125 cases and 8352 controls whose specific occupation could be identified. Seven specific occupations with an increased risk of job change were identified: cooks/chefs, hairdressers, gardeners, welders, sheet metal workers, cleaners and agricultural labourers (table 3).

To further explore the relationship between exposure and job change, we assessed occupational exposures for participants using the N-JEM. In a model using exposure groups, occupations defined by the N-JEM as having a high probability of exposure to irritating and HMW agents showed the highest ORs of job change (table 4 , model 1 ). When analysing specific exposure subgroups from the N-JEM, the exposures with the highest risk of job change differed by gender (table 4, model 2). Specifically, the highest ORs were for metalworking fluids, animal-derived agents and cleaning agents among women, and mixed agricultural work (not animal), and welding and soldering fumes and other metal dust among men.

\section{DISCUSSION}

For the first time, an association between certain occupations and job change has been demonstrated in a sample from the general population. The identified high-risk occupations were cooks/chefs, hairdressers, gardeners, welders, sheet metal workers, cleaners and agricultural labourers. The exposures with the highest risk of job change differed by gender, showing the highest ORs for metalworking fluids, animal-derived agents and cleaning agents among women, and mixed agricultural work (not animal), and welding and soldering fumes and other metal dust among men. An association between occupational exposure and respiratory symptoms or diseases for gardeners has not previously been shown.

There is limited knowledge regarding the association between exposures and respiratory symptoms or diseases for some of the identified occupations. Gardeners may be considered to have an ideal job allowing them to work outside in a natural environment. On the other hand, biological dust exposure in farmers has been associated with obstructive respiratory diseases and may explain this finding. Gardeners may also be exposed to mineral dust from soil, sand and gravel. The same exposures are probably relevant for the agricultural labourers, who are participants working on, but not living on, farms. Studies have shown increased prevalence of asthma among cleaners, ${ }^{16-18}$ hairdressers $^{13}{ }^{19-20}$ and welders. ${ }^{21-23}$ Nevertheless, having respiratory symptoms or a disease does not necessarily mean having a disability. ${ }^{1}$ Our findings identify occupations at high risk and specific exposures that may force workers to leave their workplace: information that is crucial for targeted workplace interventions and for the prevention of disability.

Our results support earlier findings from cross-sectional and prospective studies showing that breathing problems at work may lead to work disability for a substantial proportion of working-age adults. $^{2}{ }^{3}$ In Telemark County, $1.7 \%$ of those ever employed from the general population (16-50 years) reported having changed their job due to respiratory symptoms attributed to workplace exposures. Self-reported workplace exposures to metals/gases, exercise/cold, cleaning/cooking and hair products/ animals were associated with increased prevalence of job change. In our study, it seems that associations are stronger for the JEM-derived exposure measures than for the self-reported exposures (eg, cleaning agents).

Compared with our results, a higher prevalence $(4 \%)$ of respiratory work disability was reported in a cross-sectional study of the Swedish part of the European Community Respiratory Health Survey (ECRHS). ${ }^{2}$ Adjusting for covariates, the ECRHS study found that self-reported job exposure to VGDF was associated with respiratory work disability $(\mathrm{OR}=4.3,95 \%$ CI 2.2 to 8.6). This is consistent with our findings for those who had ever been exposed $(\mathrm{OR}=5.6,95 \% \mathrm{CI}$ 4.0 to 8.0$)$. Eighty-four per cent of the 247 workers who changed their jobs due to respiratory symptoms reported that they had been exposed to VGDF compared with $48.6 \%$ among the ever employed controls $(\mathrm{OR}=5.6,95 \% \mathrm{CI} 4.0$ to 8.0$)$. This finding may be biased by the disease status of those reporting a job change, and underlines the importance of using data from a JEM rather than from a self-report. ${ }^{5}$ It is also noted that

Table 3 Risk of job change for occupations with at least 3 cases registered, and by gender

\begin{tabular}{|c|c|c|c|c|c|c|}
\hline ISCO-88 code and occupation & $\begin{array}{l}\text { Cases } \\
(n=125)\end{array}$ & $\begin{array}{l}\text { Controls } \\
(n=8352)\end{array}$ & $\mathrm{OR}_{\text {Crude }}(95 \% \mathrm{Cl})$ & $\mathrm{OR}_{\mathrm{adj}}{ }^{*}(95 \% \mathrm{Cl})$ & $\begin{array}{l}\text { Females }(n=47) O R_{a d j}{ }^{*} \\
(95 \% \mathrm{Cl})\end{array}$ & $\begin{array}{l}\text { Males }(\mathrm{n}=78) \mathrm{OR}_{\text {adj }}{ }^{*} \\
(95 \% \mathrm{Cl})\end{array}$ \\
\hline 3230 Nurses (\%) & $3(2)$ & $303(3.6)$ & 0.65 (0.21 to 2.1$)$ & $1.2(0.37$ to 3.9$)$ & $1.6(0.46$ to 5.3$)$ & - \\
\hline $\begin{array}{l}3229 \text { Health-associated } \\
\text { professionals (except nursing) (\%) }\end{array}$ & $6(5)$ & $572(6.8)$ & $0.69(0.30$ to 1.6$)$ & $1.3(0.53$ to 3.0$)$ & $1.4(0.5$ to 3.7$)$ & $1.7(0.23$ to 13$)$ \\
\hline 5122 Cooks/chefs (\%) & 7 (6) & $196(2.3)$ & 2.5 (1.1 to 5.4$)$ & $3.6(1.6$ to 8.0$)$ & $5.5(2.2$ to 14$)$ & 1.3 (0.17 to 9.6$)$ \\
\hline 5141 Hairdressers (\%) & $5(4)$ & $92(1.1)$ & 3.7 (1.5 to 9.4$)$ & $6.4(2.4$ to 17$)$ & 8.6 (3.1 to 24$)$ & - \\
\hline 5220 Shop salespersons (\%) & $8(6)$ & $1127(13.5)$ & $0.44(0.21$ to 0.90$)$ & $0.75(0.35$ to 1.6$)$ & $1.0(0.37$ to 2.7$)$ & $0.58(0.18$ to 1.9$)$ \\
\hline 6113 Gardeners (\%) & $3(2)$ & $47(0.6)$ & $4.3(1.3$ to 14$)$ & 4.5 (1.3 to 15$)$ & - & $5.3(1.5$ to 18$)$ \\
\hline 7124 Carpenters and joiners (\%) & $6(5)$ & $176(2.1)$ & $2.3(1.0$ to 5.4$)$ & 2.3 (0.98 to 5.5$)$ & - & $2.2(0.92$ to 5.2$)$ \\
\hline 7212 Welders (\%) & $5(4)$ & $53(0.6)$ & 6.5 (2.4 to 17$)$ & $5.2(2.0$ to 14$)$ & - & $5.0(1.9$ to 13$)$ \\
\hline 7213 Sheet metal workers (\%) & $5(4)$ & $50(0.6)$ & 6.9 (2.7 to 18$)$ & $5.4(2.0$ to 14$)$ & - & $5.1(1.9$ to 14$)$ \\
\hline $\begin{array}{l}7230 \text { Machinery mechanics } \\
\text { and fitters (\%) }\end{array}$ & $5(4)$ & $155(1.9)$ & 2.2 (0.89 to 5.5$)$ & $2.0(0.81$ to 5.2$)$ & 22 (2.6 to 191$)$ & 1.6 (0.56 to 4.4$)$ \\
\hline 7231 Motor vehicle fitters (\%) & $3(2)$ & $112(1.3)$ & $1.8(0.57$ to 5.9$)$ & $1.7(0.51$ to 5.4$)$ & - & $1.6(0.50$ to 5.3$)$ \\
\hline $\begin{array}{l}8332 \text { Earth moving and related plan } \\
\text { operators (\%) }\end{array}$ & $4(3)$ & $101(1.2)$ & 2.7 (0.89 to 7.5$)$ & $2.5(0.88$ to 7.1$)$ & - & 2.4 (0.84 to 6.8$)$ \\
\hline 9131 and 9132 Cleaners (\%) & $7(6)$ & $152(1.8)$ & $3.2(1.5$ to 7.0$)$ & $5.0(2.2$ to 11$)$ & 5.7 (2.3 to 14$)$ & $3.9(0.51$ to 31$)$ \\
\hline 9211 Agricultural labourers (\%) & $4(3)$ & $44(0.5)$ & $6.2(2.2$ to 18$)$ & 7.4 (2.5 to 22$)$ & 12 (2.6 to 57$)$ & $5.3(1.2$ to 24$)$ \\
\hline
\end{tabular}


Table 4 Risk of job change by occupational exposure category* and gender

\begin{tabular}{|c|c|c|c|}
\hline Exposure category & $\begin{array}{l}\text { Total }\left(n_{\text {cases }}=125\right) \\
\mathrm{OR}_{\text {adj }}(95 \% \mathrm{Cl}) \dagger\end{array}$ & $\begin{array}{l}\text { Females }(n=47) \\
\mathrm{OR}_{\text {adj }}(95 \% \mathrm{Cl}) \neq\end{array}$ & $\begin{array}{l}\text { Males }(n=78) \\
\mathrm{OR}_{\text {adj }}(95 \% \mathrm{Cl}) \neq\end{array}$ \\
\hline \multicolumn{4}{|l|}{ Regression model 1} \\
\hline HMW agents & 2.5 (1.5 to 4.4$)$ & $2.4(1.1$ to 5.2$)$ & $2.7(1.2$ to 5.9$)$ \\
\hline LMW agents & $1.7(1.0$ to 2.9$)$ & 4.1 (1.7 to 9.9$)$ & 1.3 (0.69 to 2.4$)$ \\
\hline Irritating agents & 2.5 (1.6 to 3.8$)$ & $2.7(1.4$ to 5.4$)$ & $2.4(1.4$ to 4.2$)$ \\
\hline Peak exposure to irritants & $2.3(1.3$ to 4.2$)$ & $1.2(0.15$ to 9.4$)$ & $2.7(1.4$ to 5.0$)$ \\
\hline Uncertain or low exposure & $1.4(0.64$ to 3.0$)$ & $1.6(0.38$ to 7.0$)$ & $1.3(0.51$ to 3.2$)$ \\
\hline \multicolumn{4}{|l|}{ Regression model 2} \\
\hline Animal-derived agents & $3.2(0.88$ to 12$)$ & $13(3.4$ to 49$)$ & $0.61(0.063$ to 6.0$)$ \\
\hline Mixed agricultural work (not animal) & $5.3(1.8$ to 15$)$ & $5.3(0.68$ to 41$)$ & $4.8(1.4$ to 17$)$ \\
\hline Moulds and other bio-aerosols & $1.6(0.45$ to 5.6$)$ & $0.28(0.026$ to 2.9$)$ & $3.7(1.1$ to 13$)$ \\
\hline Latex proteins & 1.7 (0.46 to 6.7$)$ & $2.2(0.51$ to 10$)$ & - \\
\hline Pharmaceutical product agents & $0.83(0.15$ to 4.5$)$ & $0.95(0.15$ to 5.8$)$ & - \\
\hline Acrylates & $1.0(0.23$ to 1.8$)$ & - & $0.78(0.20$ to 4.7$)$ \\
\hline Epoxy chemicals & $0.38(0.080$ to 1.8$)$ & - & $0.47(0.087$ to 2.6$)$ \\
\hline Diisocyanates & 1.7 (0.67 to 4.5$)$ & $2.6(0.28$ to 23$)$ & 1.5 (0.53 to 4.3$)$ \\
\hline Reactive agents (aldehydes, amines, etc) & $4.7(2.2$ to 10$)$ & 8.1 (3.0 to 22 ) & $2 . .6(0.73$ to 8.9$)$ \\
\hline Cleaning agents & $5.6(2.4$ to 13$)$ & 8.8 (3.4 to 23$)$ & $2.1(0.28$ to 16$)$ \\
\hline Wood and paper dust & 3.7 (1.9 to 7.2$)$ & $6.7(0.70$ to 64$)$ & $2.8(1.3$ to 5.8$)$ \\
\hline Inorganic dust and fumes & $2.1(1.1$ to 3.8$)$ & - & 2.1 (1.1 to 3.9$)$ \\
\hline Welding and soldering fumes and other metal dust & $4.0(1.3$ to 12$)$ & - & $4.4(1.2$ to 16$)$ \\
\hline Metalworking fluids & $1.7(0.59$ to 4.7$)$ & 27 (3.2 to 237) & $1.0(0.34$ to 3.2$)$ \\
\hline Vehicle/motor exhaust & $2.2(1.2$ to 4.1$)$ & $3.2(1.2$ to 8.3$)$ & 1.7 (0.79 to 3.6$)$ \\
\hline Peak exposure to irritants & $1.6(0.59$ to 4.4$)$ & $1.5(0.16$ to 14$)$ & $1.4(0.43$ to 4.8$)$ \\
\hline Uncertain or low exposure & $1.5(0.71$ to 3.4$)$ & 2.3 (0.52 to 9.9$)$ & 1.2 (0.49 to 3.1$)$ \\
\hline
\end{tabular}

employment status in the past 12 months and the frequency of self-reported occupational exposures to VGDF did not vary substantially by responder status in the initial study (the Telemark study), indicating that non-response bias was less likely.

Cross-sectional analysis of data from the complete ECRHS cohort found that $3.6 \%$ of adults aged $20-44$ reported job change due to breathing difficulties at work. ${ }^{3}$ In this international study, structured interviews from a random sample of 15039 participants were analysed on the basis of surveys conducted in 12 European and 4 non-European countries. The lowest national estimate was $1.1 \%$ for participants from Norway, which is somewhat less than the current estimate of $1.7 \%$. Many countries that contributed to the ECRHS had substantially higher percentages for job change due to breathing difficulties, perhaps the result of differences in national policies on accommodating workers with health problems aggravated by occupational exposures.

The incidence of new-onset respiratory disability was also assessed in a 2009 international prospective general populationbased study, which included participants from the ECRHS I and II. ${ }^{4}$ In the ECRHS, no data were available regarding specific occupational exposures, but in the 2009 study, more than half of all participants reported exposure to VGDF at work and $15 \%$ reported exposure to high levels. This is in agreement with data from our study showing that $49 \%$ reported being exposed to VGDF and $17 \%$ reported exposure on a daily basis.

Our results indicate that there may be differences between men and women regarding the risk of respiratory work disability. Indications of differences were most clearly present when we assessed exposures based on the N-JEM and related them directly to job change, showing higher ORs among females than males for several exposures. Whether women are more susceptible to exposure at work or could be more prone to changing workplaces than men remains a matter of speculation. Another explanation might be that in some occupations, women may have a higher exposure than men. However, other studies have not been able to detect a sex-related difference in disability, ${ }^{2}$ and the number in each group in our study was small. Hence, others should confirm these results.

There are few studies reporting risk estimates for job change by occupation or specific occupational exposures. In a study among Swedish pulp mill workers, it was shown that irritant peak exposure during gassing episodes was a strong predictor of changing work due to respiratory problems, even after adjustment for asthma, chronic bronchitis and chronic rhinitis. ${ }^{24}$ This is consistent with findings from our analysis using crude exposure groups in the regression model (table 4, model 1). In our data, several of the identified specific exposures fit with the occupations showing an increased risk of job change, such as cleaning agents and cleaners, mixed agricultural work and gardeners or agricultural labourers, and irritating agents and hairdressers. Beforehand, we expected that certain jobs and exposures would be associated with job change, such as for bakers. In this study, bakers did not report job change because work affected their breathing more often than others. The lack of an association between respiratory symptoms at work and job change for some occupations and exposures could be attributable to sample size (bakers $n=25$ ) or could reflect that for 
certain jobs and exposures workers may continue to work even if they do develop respiratory symptoms. Whether certain jobs and exposures are associated with respiratory symptoms but not with job change will be assessed in further analyses.

Our study has important limitations. We used job change attributed to breathing difficulties based on self-reports as a surrogate for respiratory occupational disability. The survey did not independently collect and validate employment data, nor did it specifically assess the complete cessation of employment for health-related reasons. We used an independent measure of exposure (JEM), which is considered to reduce the risk of recall bias regarding previous exposure. ${ }^{6}$ Other researches have assigned to repondents the occupation the paticipants themself reported to have led to job change because their breathing was affected. We also applied that approach in our data, but did not find that the results differed substantially (data not shown). Using occupations from a JEM provides the advantage of comparable exposure assessment for cases and controls. However, our estimates of relative risk may be lower than the true values because of non-differential misclassification of exposure. For example, an equal proportion of cases and controls may have reported a job assessed by the JEM as being exposed, but personally received no or low exposure because they did not perform the tasks where exposure occurred (eg, a nurse not using disinfectants or a welder performing mostly administrative work). Also, the variable used to determine work disability 'Have you ever had to change or leave your job because it affected your breathing?' may have missed some cases, for example, for individuals who modified their job but retained the same job title and employer. While this may have occurred for only a few participants, and may not have affected the comparison between occupational groups, it may have led to an underestimate of the total numbers affected.

It may be considered that general discontent with work could lead to job change. We think such discontent would not consistently be associated with any one type of job/exposure. If the discontent is scattered across jobs or exposures, then there could be non-differential misclassification of the outcome (ie, non-differential with respect to exposure), which would bias estimates of association to the null. An underestimation might also have occurred if our sample included participants who self-selected into less exposed jobs because of respiratory symptoms or conditions, because we were not able to adjust for this bias.

To some extent, the likelihood of changing or leaving work might be related to income. This may have been the case if the development of respiratory symptoms did not lead to job change because the work was highly paid or valued. We did not have the possibility to adjust for income. However, as shown in table 2, the prevalence of respiratory symptoms and asthma was two to three times higher in cases compared with controls. If there were a substantial number of workers experiencing symptoms and not changing or leaving their job, this would most likely have attenuated that difference. It may also be considered as a limitation that we had few participants $(\mathrm{n}=125)$ who specified their job in the year prior to job change. Nevertheless, we had more exposure information on the larger sample $(n=247)$ than previous studies have had when assessing respiratory work disability. ${ }^{2}{ }^{3}$ Also, our findings from the smaller sample $(n=125)$ are in line with those from the 247 participants and demonstrate similar findings using different methods (self-report vs JEM data, and also with different statistical methods) in two samples from the general population. Moreover, a median of 50 controls per case were included in the analyses to increase the precision of the results. Non-response to the postal questionnaire in this study has been assessed ${ }^{12}$ and showed that responders and non-responders had similar frequencies of respiratory symptoms, except that chronic coughing was somewhat higher in non-responders. The prevalence of physician-diagnosed asthma was $12 \%$ in responders and $11.5 \%$ in non-responders. These results indicate that non-response bias is less likely for the frequency of these conditions and symptoms, and that the external validity for similar populations may be good. Nonetheless, the results may not be extended to countries with substantially different social security systems than that in Norway. In Norway, employers are strongly encouraged by the authorities to facilitate adjustments in the workplace when symptoms occur among workers, which in turn may limit the need for job change.

In summary, we found that $1.7 \%$ of working-age adults ever employed reported job change because exposures at work affected their breathing. For the first time, associations between specific occupations and respiratory work disability were demonstrated in a sample from the general population, based on detailed exposure data. The 'breath-taking jobs' (occupations with significant increase in the risk of job change) were cooks/ chefs, welders, gardeners, sheet metal workers, cleaners, hairdressers and agricultural labourers. We also found that several specific occupational exposures, assessed with an asthma-specific JEM, were associated with an increased risk of job change, with some differences between genders. Our findings indicate that these exposures and occupations still need to be addressed through preventive measures.

Acknowledgements The authors thank MSc student Jakob Sebastian Fell, Norwegian Technical University of Trondheim, Norway for plotting, verifying and categorising exposure data, and Oscar Espeland, MSc, Sintef Molab AS, Porsgrunn, Norway for advice and assistance on the collection and categorising of exposure data.

Contributors AKMF was involved in the conception and design of the study, data acquisition, data management, data interpretation and primary manuscript preparation. RA was involved in the design of the study, data acquisition, data management, data interpretation and critical revision of the manuscript. PKH contributed to the design of the study, data interpretation and critical revision of the manuscript. MVS was involved in the conception and design of the study, data acquisition, data management, analyses, and interpretation and critical revision of the manuscript. EA contributed to the data interpretation and critical revision of the manuscript. KT contributed to the design of the study, data interpretation and critical revision of the manuscript. JK was involved in the conception and design of the study, data interpretation and critical revision of the manuscript. All authors approved the final version of the manuscript.

Funding This work was supported by funding from Telemark Hospital, Norway. Competing interests None declared.

\section{Patient consent Obtained.}

Ethics approval The Regional Committee for Medical and Health Research Ethics Southeast Norway, ID2012/1665.

Provenance and peer review Not commissioned; externally peer reviewed.

Open Access This is an Open Access article distributed in accordance with the Creative Commons Attribution Non Commercial (CC BY-NC 4.0) license, which permits others to distribute, remix, adapt, build upon this work non-commercially, and license their derivative works on different terms, provided the original work is properly cited and the use is non-commercial. See: http://creativecommons.org/ licenses/by-nc/4.0/

\section{REFERENCES}

1 Verbeek J, van Dijk F. Assessing the ability to work. BMJ 2008;336:519-20.

2 Blanc PD, Ellbjär S, Janson C, et al. Asthma-related work disability in Sweden. The impact of workplace exposures. Am J Respir Crit Care Med 1999;160:2028-33.

3 Blanc PD, Burney P, Janson C, et al. The prevalence and predictors of respiratory-related work limitation and occupational disability in an international study. Chest 2003;124:1153-9. 
4 Torén $\mathrm{K}$, Zock JP, Kogevinas $\mathrm{M}$, et al. An international prospective general population-based study of respiratory work disability. Thorax 2009;64:339-44.

5 Delclos GL, Gimeno D, Arif AA, et al. Occupational exposures and asthma in health-care workers: comparison of self-reports with a workplace-specific job exposure matrix. Am J Epidemiol 2009;169:581-7.

6 Vandenplas 0, Torén K, Blanc PD. Health and socioeconomic impact of work-related asthma. Eur Respir J 2003;22:689-97.

7 Eisner MD, Yelin EH, Katz PP, et al. Risk factors for work disability in severe adult asthma. Am J Med 2006;119:884-91.

8 International Labour Organization. International Standard Classification of Occupations: ISCO 88. Geneva: International Labour Organization, 1991.

9 European Community Respiratory Health Survey II Steering Committee. The European Community Respiratory Health Survey II. Eur Respir J 2002;20:1071-9.

10 Kogevinas M, Zock JP, Jarvis D, et al. Exposure to substances in the workplace and new-onset asthma: an international prospective population-based study (ECRHS-II). Lancet 2007;370:336-41.

11 Lötvall J, Ekerljung L, Rönmark EP, et al. West Sweden Asthma Study: prevalence trends over the last 18 years argues no recent increase in asthma. Respir Res 2009:10:94.

12 Abrahamsen R, Svendsen MV, Henneberger PK, et al. Non-response in a cross sectional study of respiratory health in Norway. BMJ Open 2016;6:e009912.

13 Lillienberg L, Andersson E, Janson C, et al. Occupational exposure and new-onset asthma in a population-based study in Northern Europe (RHINE). Ann Occup Hyg 2013;57:482-92.

14 Lillienberg L, Dahlman-Höglund A, Schioler L, et al. Exposures and asthma outcomes using two different job exposure matrices in a general population study in Northern Europe. Ann Occup Hyg 2014;58:469-81.
15 Kennedy SM, Le Moual N, Choudat D, et al. Development of an asthma specific job exposure matrix and its application in the epidemiological study of genetics and environment in asthma (EGEA). Occup Environ Med 2000;57:635-41.

16 Vizcaya D, Mirabelli MC, Antó JM, et al. A workforce-based study of occupational exposures and asthma symptoms in cleaning workers. Occup Environ Med 2011;68:914-19.

17 Zock JP, Plana E, Jarvis D, et al. The use of household cleaning sprays and adult asthma: an international longitudinal study. Am J Respir Crit Care Med 2007;176:735-41.

18 Jaakkola JJ, Piipari R, Jaakkola MS. Occupation and asthma: a population-based incident case-control study. Am J Epidemiol 2003;158:981-7.

19 Lysdal SH, Mosbech H, Johansen JD, et al. Asthma and respiratory symptoms among hairdressers in Denmark: results from a register based questionnaire study. Am J Ind Med 2014;57:1368-76.

20 Helaskoski $E$, Suojalehto $H$, Virtanen $H$, et al. Occupational asthma, rhinitis, and contact urticaria caused by oxidative hair dyes in hairdressers. Ann Allergy Asthma Immunol 2014;112:46-52.

21 Karjalainen A, Kurppa K, Virtanen $\mathrm{S}$, et al. Incidence of occupational asthma by occupation and industry in Finland. Am J Ind Med 2000;37:451-8.

22 Lillienberg L, Zock JP, Kromhout $\mathrm{H}$, et al. A population-based study on welding exposures at work and respiratory symptoms. Ann Occup Hyg 2008;52:107-15.

23 Bakerly ND, Moore VC, Vellore AD, et al. Fifteen-year trends in occupational asthma: data from the Shield surveillance scheme. Occup Med (Lond) 2008;58:169-74.

24 Murgia N, Torén K, Kim JL, et al. Risk factors for respiratory work disability in a cohort of pulp mill workers exposed to irritant gases. BMC Public Health 2011;11:689. 